\title{
Erratum to: Psychosocial, educational, and somatic factors in chronic nonspecific low back pain
}

Edit Vereckei • Eva Susanszky • Maria Kopp - Istvan Ratko • Agnes Czimbalmos •

Zsolt Nagy • Eva Palkonyai - Laszlo Hodinka - Peter I. Temesvari •

Emese Kiss · Klara Töro $\cdot$ Gyula Poor

Published online: 25 May 2013

(c) Springer-Verlag Berlin Heidelberg 2013

Erratum to: Rheumatol Int (2013) 33:587-592

DOI 10.1007/s00296-012-2398-0

Unfortunately, there is a swap between first and family name of complete author group in the published article. The correct author group is given below.

Edit Vereckei · Eva Susanszky · Maria Kopp · Istvan Ratko · Agnes Czimbalmos - Zsolt Nagy · Eva Palkonyai - Laszlo Hodinka · Peter I. Temesvari - Emese Kiss · Klara Töro · Gyula Poor

The online version of the original article can be found under doi:10.1007/s00296-012-2398-0.

E. Vereckei $(\varangle) \cdot$ L. Hodinka · E. Kiss · G. Poor

National Institute of Rheumatology and Physiotherapy,

Budapest, Hungary

e-mail: drvereckei@gmail.com

E. Susanszky · M. Kopp

Institute of Behavioral Sciences, Semmelweis University,

Budapest, Hungary

I. Ratko

Gabor Denes College, Budapest, Hungary

A. Czimbalmos

Hungarian Red Cross, Budapest, Hungary
Z. Nagy

II. District E. Ady Street General Practitioners Surgery, Budapest, Hungary

E. Palkonyai

Brighton and Sussex University Hospitals, Brighton, UK

P. I. Temesvari

Tameside General Hospital, Ashton-under-Lyne, UK

K. Töro

Department of Forensic Medicine, Semmelweis University, Budapest, Hungary 